\title{
Near-Infrared Excited Orthogonal Emissive Upconversion Nanoparticles for Imaging- Guided On-Demand Therapy
}

\author{
Ming Tang ${ }^{\dagger}{ }^{\dagger}$, Xiaohui Zhu ${ }^{*}{ }^{\dagger}$, Yuehong Zhang ${ }^{\dagger}$, Zeping Zhang ${ }^{\ddagger}$, Zhiming Zhang ${ }^{\dagger}$, Qingsong \\ $\mathrm{Mei}^{\S}$, Jing Zhang ${ }^{\dagger}$, Minghong $\mathrm{Wu}^{\dagger}$, Jinliang Liu ${ }^{*}, \dagger$, Yong Zhang ${ }^{*}{ }^{\dagger}, \uparrow$
}

$\uparrow$ School of Environmental and Chemical Engineering, Shanghai University, Shanghai, China, 200444.

† School of Life Sciences, Shanghai University, Shanghai, China, 200444.

$\S$ School of Biological and Medical Engineering, Hefei University of Technology, Hefei, China, 230009.

ๆ Department of Biomedical Engineering, Faculty of Engineering, National University of Singapore,

Singapore 117583.

Corresponding Author:

*E-mail: xhzhu@shu.edu.cn; liuj1@shu.edu.cn; biezy@nus.edu.sg

\section{Supplementary Information}

Supporting Information is available free of charge on ACS Publication website. The Supporting Information PDF contains Figure S1-S6, which depict additional results.

\section{Supporting Figure Captions}

Figure S1. X-ray diffraction (XRD) patterns of $\mathrm{NaErF}_{4}: \mathrm{Yb} / \mathrm{Tm}$ core (a), $\mathrm{NaErF}_{4}: \mathrm{Yb} / \mathrm{Tm} @ \mathrm{NaYF}_{4}: \mathrm{Yb}$ core-shell (b) and $\mathrm{NaErF}_{4}: \mathrm{Yb} / \mathrm{Tm} @ \mathrm{NaYF}_{4}: \mathrm{Yb} @ \mathrm{NaNdF}_{4}: \mathrm{Yb}$ coreshell-shell (c) nanoparticles. The $\mathrm{XRD}$ patterns of $\beta-\mathrm{NaErF}_{4}$ is used as reference for comparison.

Figure S2. (a-c) TEM images of $\mathrm{NaErF}_{4}, \mathrm{Yb} / \mathrm{Tm} @ \mathrm{NaYF}_{4}: \mathrm{Yb} @ \mathrm{NaYF}_{4}: 10 \% \mathrm{Yb}$, xNd UCNPs with different $\mathrm{Nd}^{3+}$ concentrations in the NaYF4:10\%Yb, $\mathrm{x} \% \mathrm{Nd}$ outer shell: $\mathrm{x}=0,45$, and 90 . (d) The intensity ratio of green to red upconversion emission at $808 \mathrm{~nm}$ with different $\mathrm{Nd}^{3+}$ concentrations in the $\mathrm{NaYF}_{4}: 10 \% \mathrm{Yb}, \mathrm{x} \% \mathrm{Nd}$ outer shell: $\mathrm{x}=0,45$, and 90 .

Figure S3. (a). UV-Vis absorption spectra of standard $\mathrm{ZnPc}$ solutions with different concentrations $(10 \mu \mathrm{g} / \mathrm{mL}, 7.5 \mu \mathrm{g} / \mathrm{mL}, 5.0 \mu \mathrm{g} / \mathrm{mL}, 2.5 \mu \mathrm{g} / \mathrm{mL}$ and $1.25 \mu \mathrm{g} / \mathrm{mL})$. (b). The calibration curve (concentration vs. absorbance) was fitted by unweighted least-squares linear regression. 
Figure S4. UV-Vis absorption spectra of supernatants of UCNPs@ $\mathrm{mSiO}_{2}-\mathrm{ZnPc}$ nanophotosensitizers collected by centrifugation after they were soaked in deionized water, PBS buffer, ethanol and cell culture medium (DMEM) for 24 hours.

Figure S5. (a). Flow cytometric analysis of intracellular ROS for different groups: group 1: A549 cells with DCFH-DA (control), group 2: A549 cells incubated with UCNPs@ $\mathrm{mSiO}_{2}-\mathrm{ZnPc}$ without laser irradiation, group 3: A549 cells incubated with UCNPs@ $\mathrm{mSiO}_{2}-\mathrm{ZnPc}$ under 808 nm laser irradiation for $10 \mathrm{~min}\left(235 \mathrm{~mW} / \mathrm{cm}^{2}\right)$ and group 4: A549 cells incubated with $\mathrm{UCNPs} @ \mathrm{mSiO}_{2}-$ $\mathrm{ZnPc}$ under $980 \mathrm{~nm}$ laser irradiation for $10 \mathrm{~min}\left(608 \mathrm{~mW} / \mathrm{cm}^{2}\right)$. The generation of intracellular ROS was monitored by an increase in fluorescence of DCF (b).

Figure S6. In vivo UCL imaging of A549 tumor-bearing mice with UCNPs@ $\mathrm{mSiO}_{2}-\mathrm{ZnPc}$ under 808 and $980 \mathrm{~nm}$ laser lights. 
Figure S1

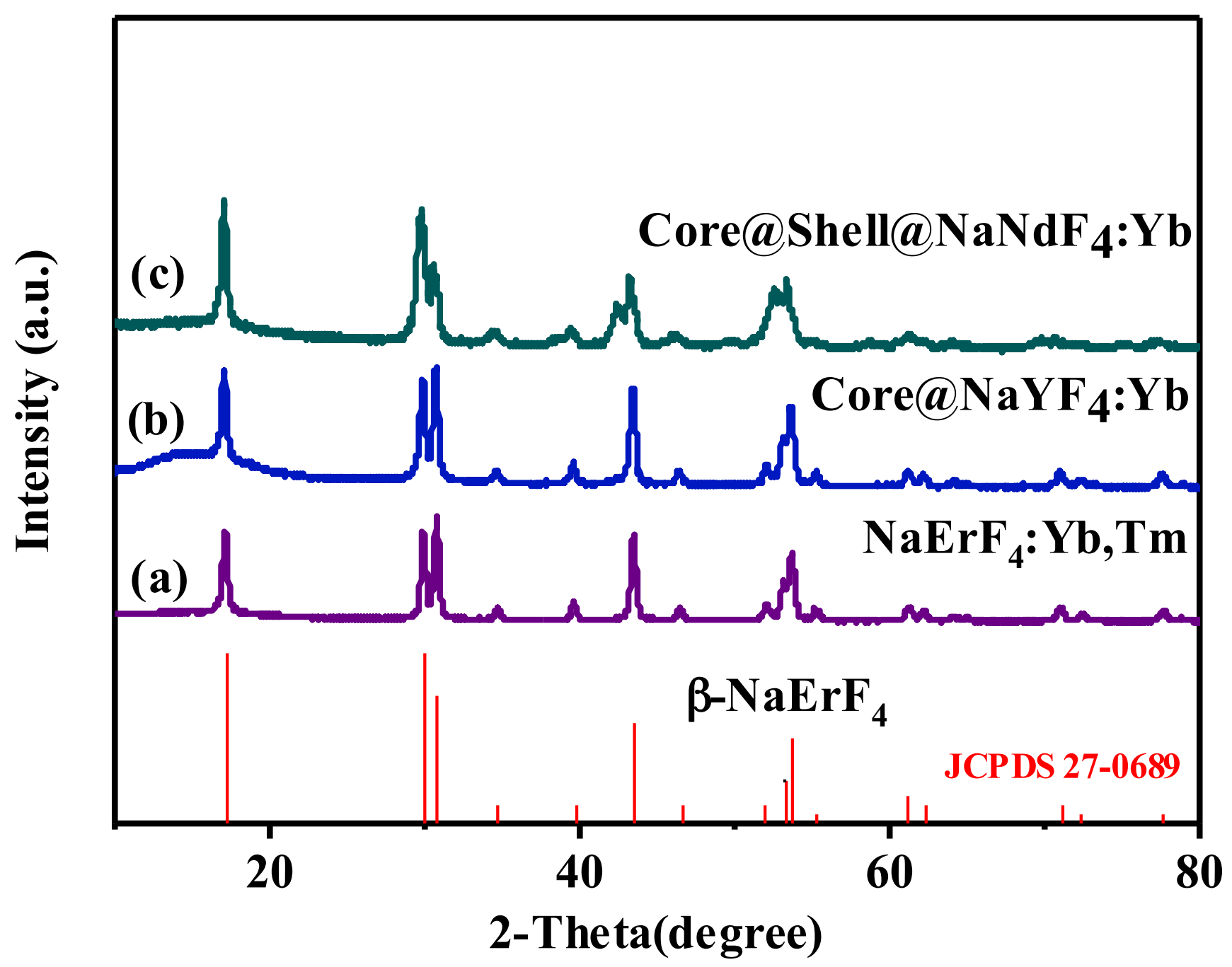


Figure S2
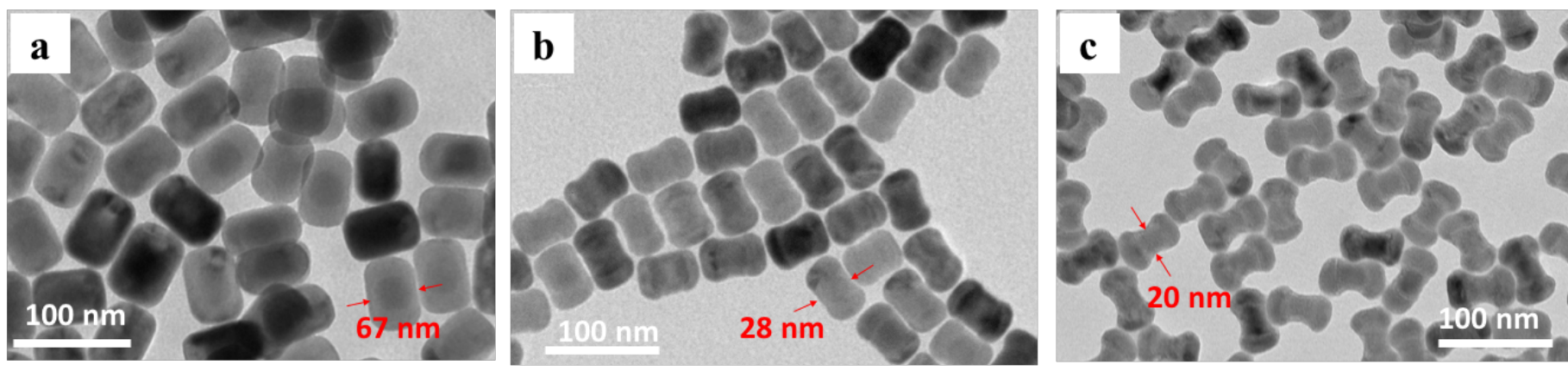

d

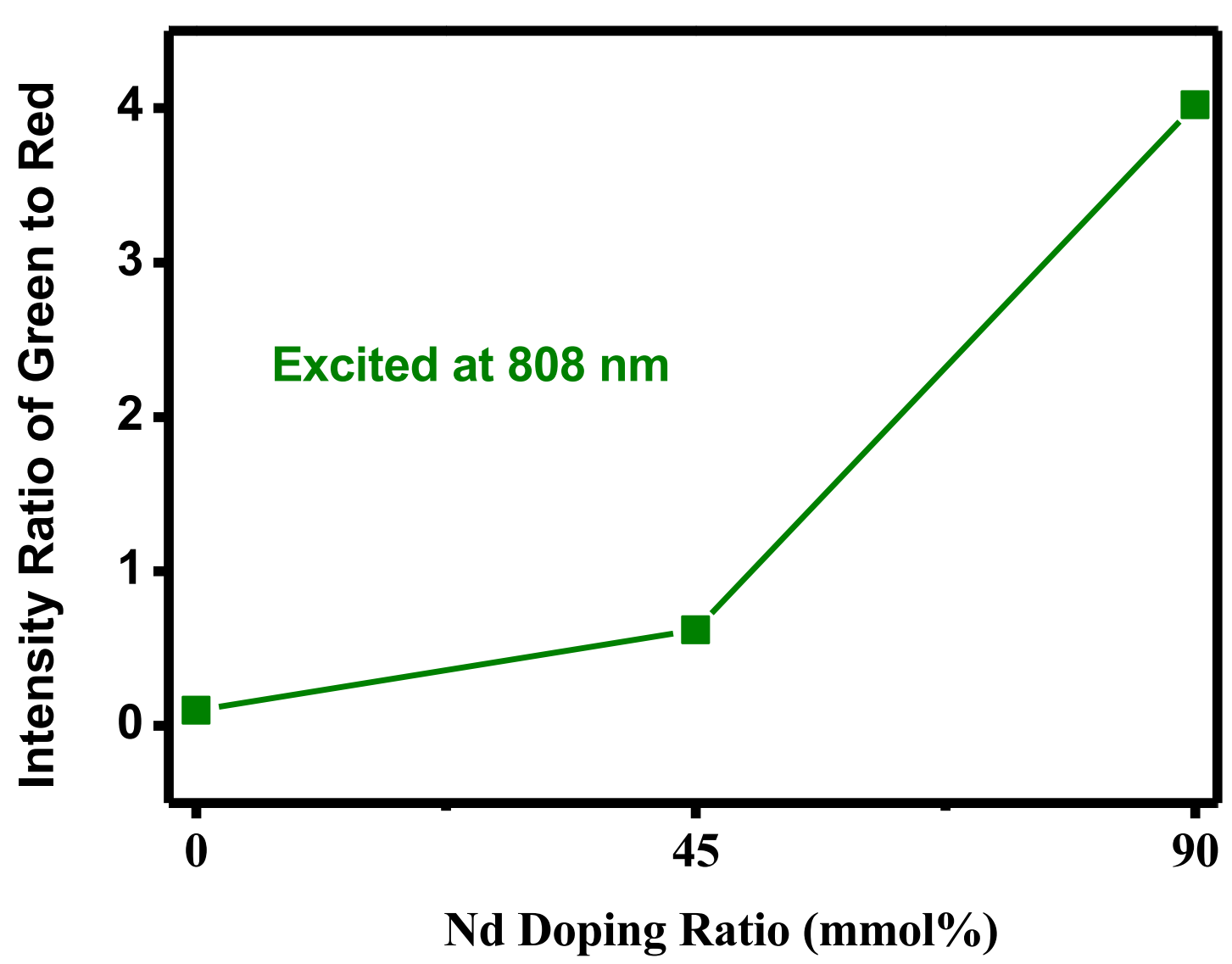


Figure S3
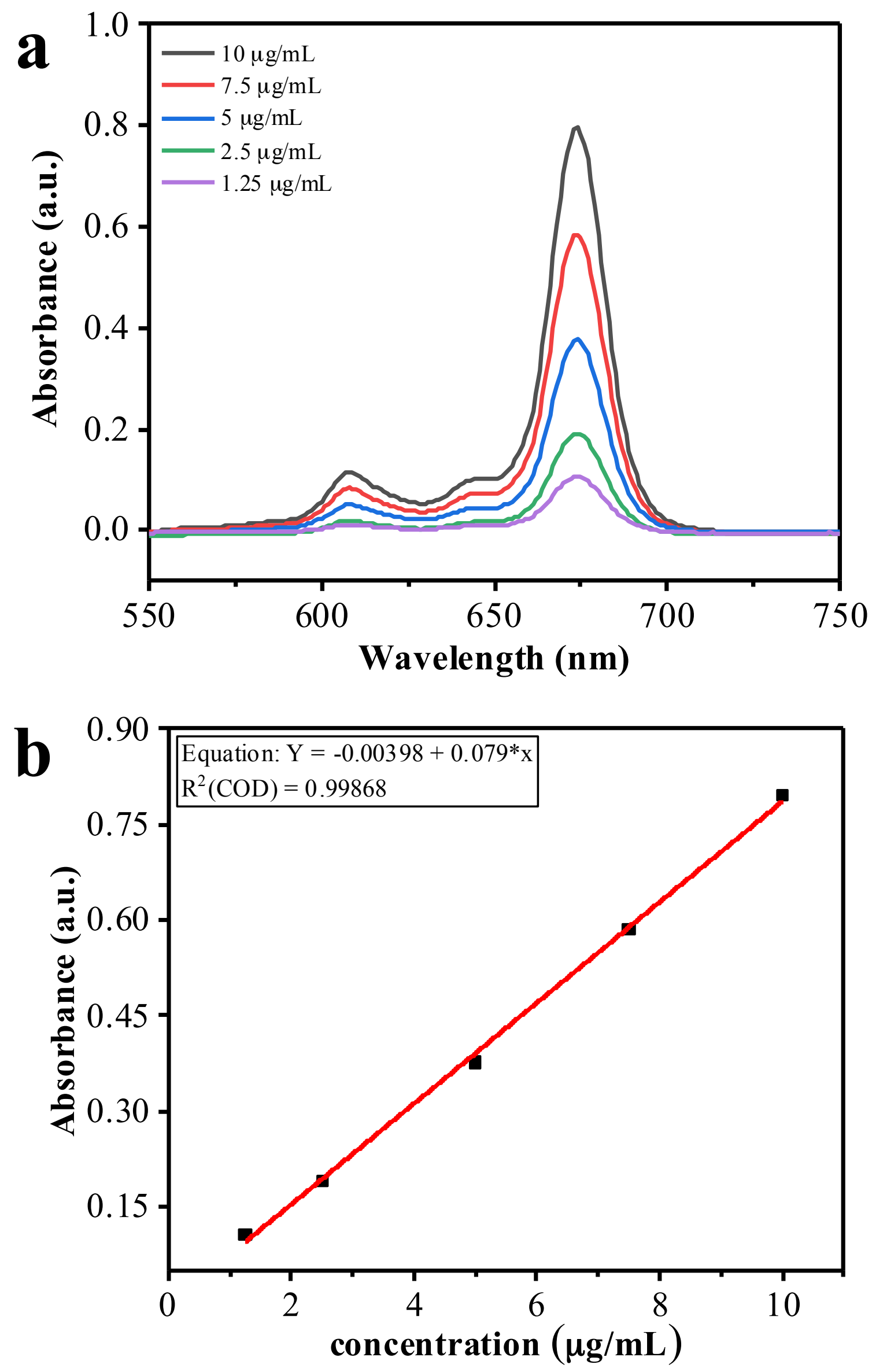
Figure S4

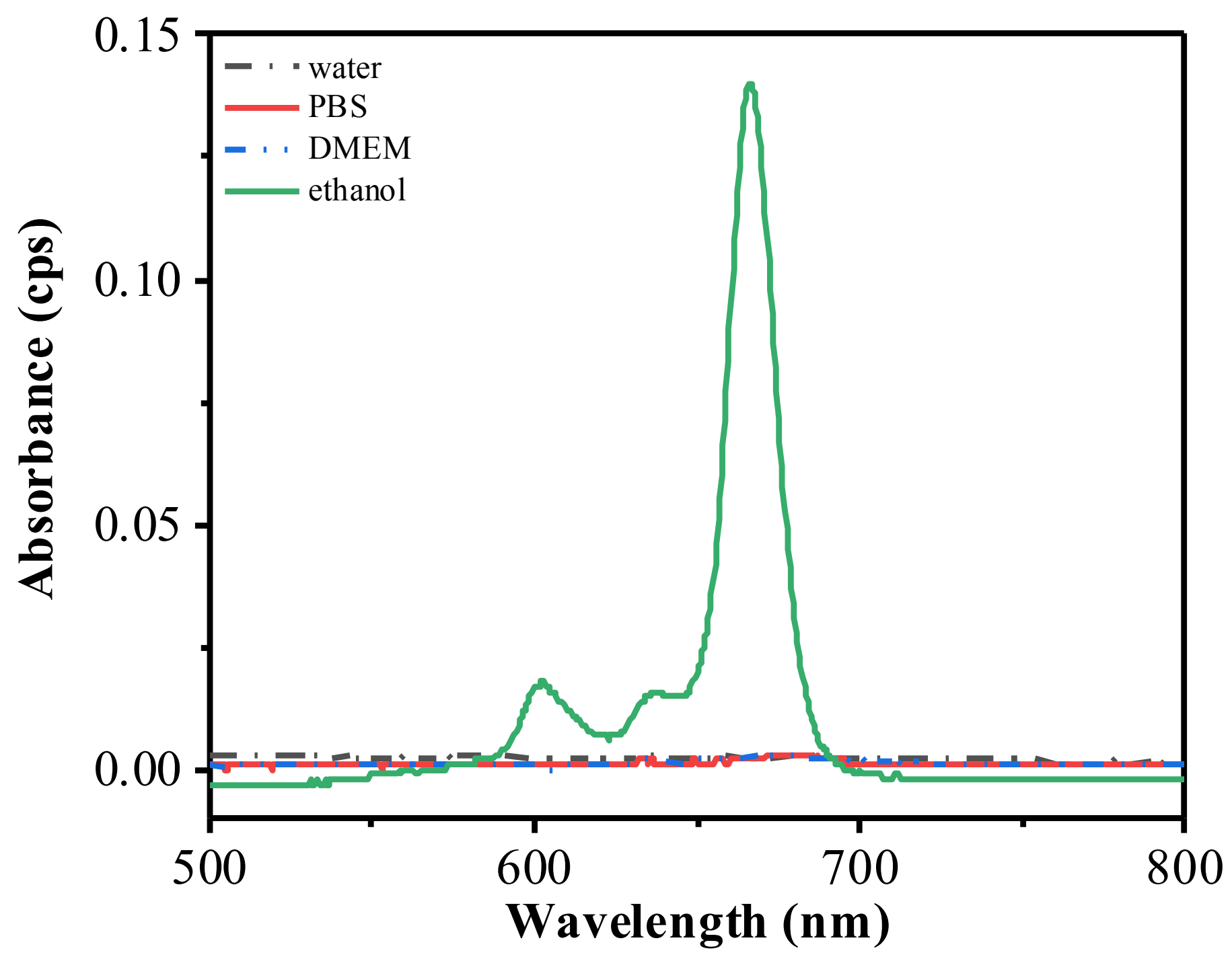



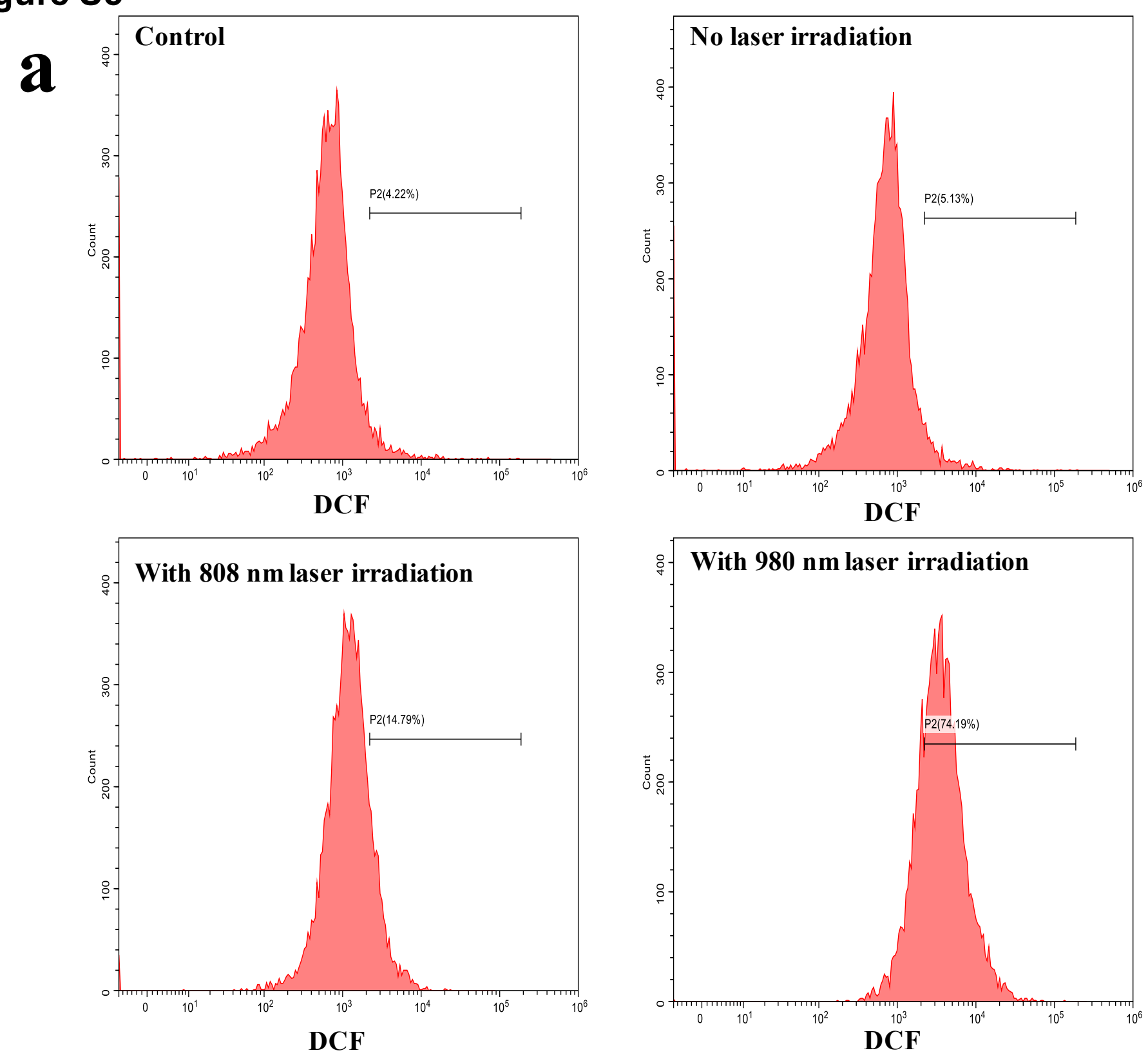

b

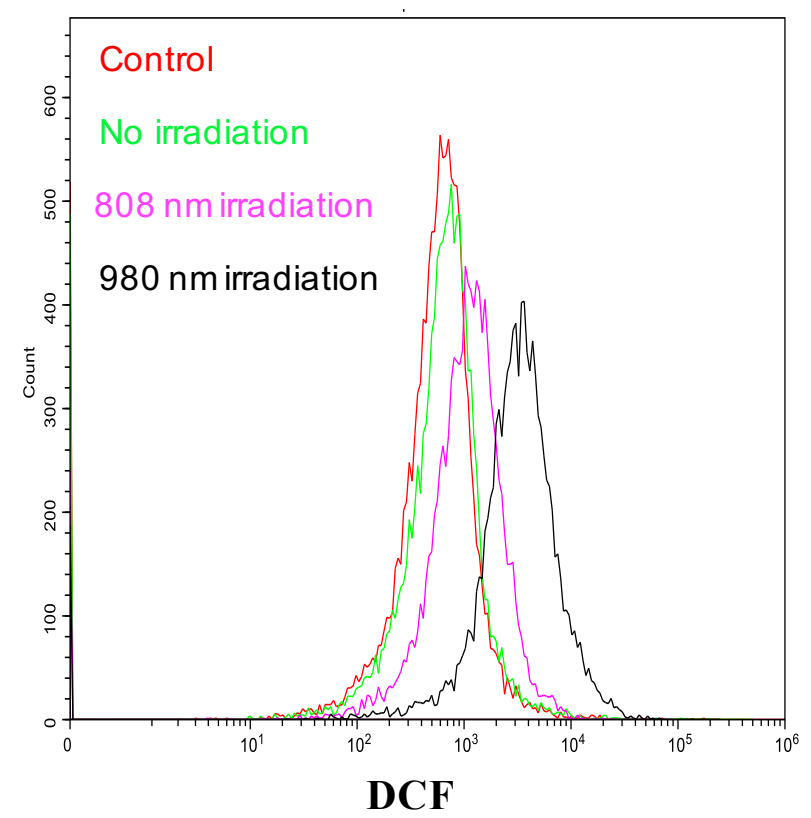


Figure S6

Excited by $808 \mathrm{~nm}$

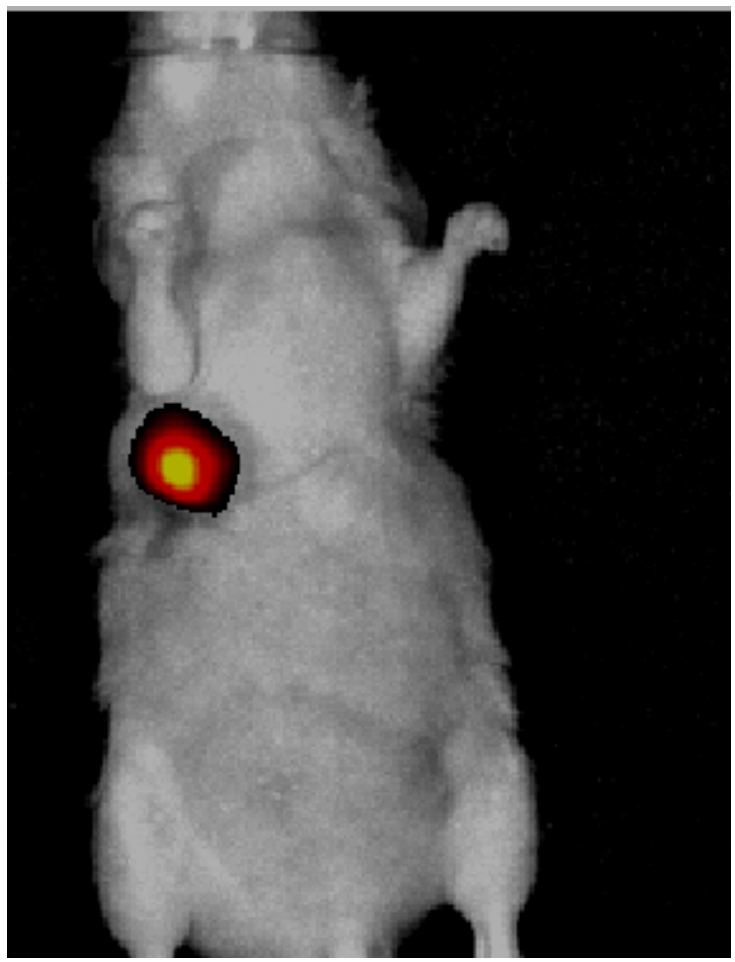

Excited by $980 \mathrm{~nm}$

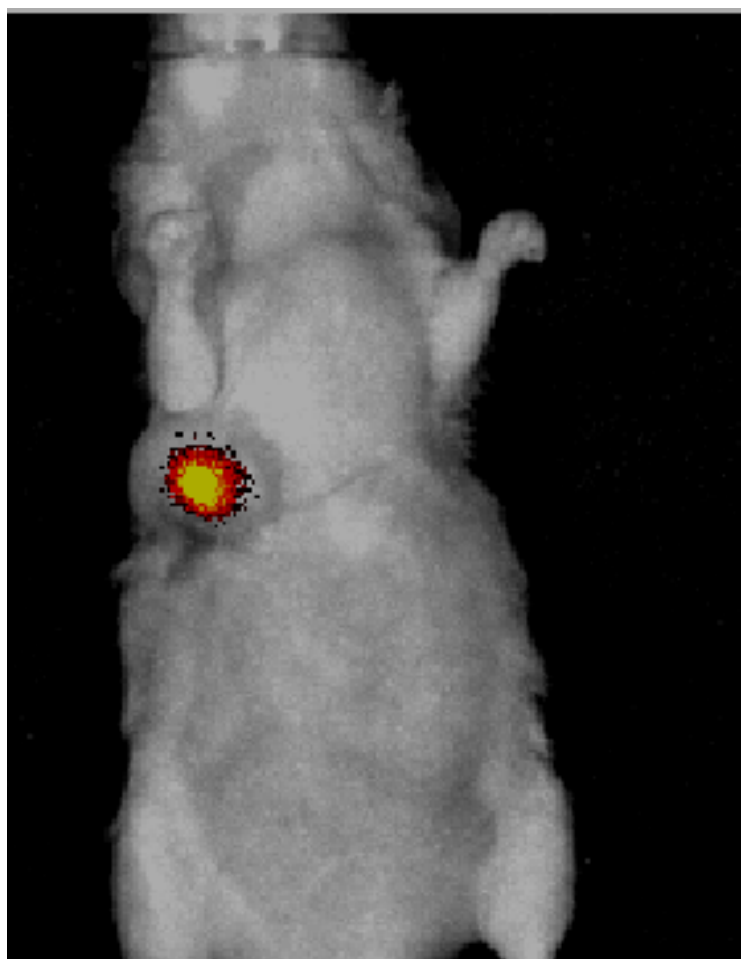

High

Low 